\title{
Barnacle walls as mediators of intertidal mussel recruitment: effects of patch size on the utilization of space
}

\author{
Sergio A. Navarrete*, Juan C. Castilla \\ Estación Costera de Investigaciones Marinas, Las Cruces. Departamento de Ecología, P. Universidad Católica de Chile, \\ Casilla 114-D, Santiago, Chile
}

\begin{abstract}
Recruitment of the competitively dominant mussel Perumytilus purpuratus to the mid rocky intertidal zone in central Chile depends upon the presence of recruitment-mediators such as mussel clumps, filamentous algae or barnacle shells. The relationship between the lateral walls of adult barnacles and the recruitment of $P$. purpuratus was investigated in a semi-sheltered rocky habitat at Las Cruces, central Chile. Changes in number of individuals and percent cover of sessile species were recorded for $8 \mathrm{mo}$ (January to September 1988) in different sized patches of bare rock. All patches were surrounded by barnacle beds. Throughout the study, $P$. purpuratus recruited only on the walls of adult barnacles that formed the patch borders, and never on bare rock. Conversely, barnacles recruited directly on the bare surface of cleared patches. Regressions of numbers of individuals in relation to patch area showed that mussel recruits outnumbered those of barnacles in patches smaller than $35.5 \mathrm{~cm}^{2}$. Above this critical patch area, the number of barnacle recruits was progressively larger than that of mussels. The area of barnacle walls suitable for mussel recruitment increases linearly with increasing patch perimeter, while the area suitable for barnacle recruitment is a function of patch area. The number of recruits was related to the substratum availability in different patch sizes, suggesting that recruitment of barnacles and mussels is not limited by larval abundance. The probability of mussels monopolizing the patches was higher in small than in large patches; the chance for barnacles to monopolize large patches increased with increasing size of patch. Consequently a barnacle-dominated substratum may change to a mussel-dominated one depending upon the relative abundances of small and large patches. A barnacle bed disrupted in several small patches will provide more substratum for mussel recruitment than if only few large patches are produced. Possible effects of patch and predator sizes on intertidal community structure are discussed.
\end{abstract}

\section{INTRODUCTION}

Intertidal mussels are conspicuous components of most temperate rocky shores communities. They are generally the superior competitors for primary space (bare rock) in these communities, forming extensive monocultures that cover a great portion of the intertidal zone (Lewis 1964, Paine 1966, Menge 1976, Seed 1976, Suchanek 1978, 1986, Castilla 1981, Paine \& Levin 1981). In central Chile the mussel Perumytilus purpuratus is able to exclude other sessile species such as algae and barnacles from the mid intertidal zone (Paine et al. 1985). Nevertheless, experiments conducted by Castilla \& Durán (1985) have shown that once P. pur-

\footnotetext{
- Present address: Department of Zoology, Cordley 3029, Oregon State University, Corvallis, Oregon 97331-2914, USA
}

puratus is removed from the rocks by predators the substratum is readily occupied by chthamaloid barnacles, which monopolize the mid intertidal zone and persist for several years, without evidence of re-colonization by mussels (Durán \& Castilla 1989).

Contrary to the 'weed strategy' of Chilean chthamaloid species (sensu Castilla 1988), Perumytilus purpuratus seems unable to recruit directly on bare rock that is continually freed from occupants by predators (Durán \& Castilla 1989). Larvae of this mussel seem to be abundant in the water column throughout the year, since they can continually recruit on conspecific byssal threads and on filamentous algae in the lower intertidal fringe (pers. obs.). Apparently, P. purpuratus needs the presence of recruitment-mediators to colonize the intertidal zone.

Recruitment-mediators have long been recognized 
for other mytilid species. For instance, filamentous material facilitates the recruitment of Mytilus edulis to the rocky intertidal zone (see Seed 1976 and Suchanek 1986 for reviews). Recruits of $M$. edulis have been found in filamentous algae, barnacles and mussel byssal threads on the coasts of Britain (Bayne 1964, Seed 1969, 1976), Ireland (McGrath et al. 1988), and North America (Menge 1976, Suchanek 1978, Petersen 1984a, Eyster \& Pechenik 1987), although different larval settlement behaviour may be involved (McGrath et al. 1988). Similarly, Mytilus californianus does not successfully recruit on patches of bare rock along the coasts of North America; the surface must have been previously colonized by filamentous algae, barnacles, or clumps of adult mussels (Harger 1972, Petraitis 1978, Suchanek 1979, 1981, Paine \& Levin 1981, Petersen $1984 a, b$, Yamada \& Peters 1988). On the northern Gulf of California, Lively \& Raimondi (1987) found no recruitment of Brachidontes semilaevis on bare rock, but abundant recruitment on clumps of barnacle.

Little is known about recruitment-mediators of Perumytilus purpuratus. Moreno et al. (1986) observed recruitment of this species in byssal threads of conspecific adults and in spaces and crevices among barnacles. There is, however, no quantitative information about such a relationship, nor of the process of $P$. purpuratus bed formation. In the present study we describe a case where the lateral walls of chthamaloid barnacles serve as recruitment-mediators for the mussel $P$. purpuratus in a semi-sheltered habitat of central Chile. We concentrate on the effects that the size of patch has on the monopolization of the patches by sessile species (i.e. barnacles and mussels) and discuss the effects of this phenomenon in the intertidal community, and the potential effects of different sized predators on the community structure.

\section{MATERIAL AND METHODS}

Observations were made in barnacle-dominated rocky platforms in the mid intertidal zone of Las Cruces $\left(33^{\circ} 30^{\prime} \mathrm{S}, 71^{\circ} 39^{\prime} \mathrm{W}\right)$, central Chile. These platforms are protected from direct wave action by rocky walls that extend above the surf zone ('post-surf platforms'; Castilla 1981). Two chthamaloid species dominated the substratum ( $>70 \%$ cover), Jehlius cirratus and Chthamalus scabrosus, in a proportion of about 1:1. Both species were considered together as 'barnacles', because of the difficulty of differentiating them in the field before they reach large sizes.

Juvenile muricid gastropods Concholepas concholepas, juvenile and adult starfish Heliaster helianthus and adult crabs Acanthocyclus gayi are predators in the area. The most abundant herbivore species was
Littorina araucana (juveniles and adults), which reached densities of over 50000 ind. $\mathrm{m}^{-2}$ among barnacles. Juvenile individuals of Collisella spp. were also found among barnacles.

An estimation of size frequency distribution of patches of bare rock was obtained by measuring the maximal length and width of all patches present in twelve $1 \mathrm{~m}^{2}$ quadrats. Positions of quadrats were chosen by dividing barnacle-dominated platforms $\left(<25^{\circ}\right.$ slope) into $1 \mathrm{~m}$ width transects and haphazardly selecting some of them. Only patches of bare rock without evidence of recolonization by sessile invertebrates or algae were considered. All these patches had apparently been produced by predators (i.e. gastropods, starfish, crabs) since there was no evidence of storms or other abiotic factors that could account for the bare rock space in this semi-sheltered habitat.

We selected 22 of these bare patches on 3 different platforms and followed the recolonization by sessile organisms from January to September 1988. Patches ranged between 1.1 and $1439.5 \mathrm{~cm}^{2}$, covering the range of sizes found in the field (see below). Monitoring was initiated a few days after patches were produced (platforms were observed every day before beginning the study) and all large predators (adults and juveniles of Concholepas concholepas and Heliaster helianthus) were removed to avoid further perturbation. Every $5 \mathrm{~d}$ during the first month and every 10 $d$ thereafter, all organisms recruiting to either the bare rocky surface of patches, or to the lateral walls of adult barnacles of the patch borders, were identified and counted. Individual field-maps of patches were drawn on transparent plates every $10 \mathrm{~d}$. In these field-maps, the perimeter of the patch at the time, as well as all new-recruited mussels and barnacles were recorded. New recruits (individuals of about 0.3 to $3.0 \mathrm{~mm}$ long) were counted only up to the 130th day. Mussel 'microbeds' (see below) precluded accurate counts after that time. We define recruitment as the process of settlement: larval attachment to substratum and metamorphosis, and survival up to a visible stage (Keough \& Downes 1982).

Measurements of patch areas and percent cover of mussels and barnacles were calculated in the laboratory from field-maps by using an electronic planimeter (Ushikata 220 L). Patch perimeters were measured by laying a string around the patch borders on the fieldmaps.

To obtain a preliminary estimate of the effects of different patch sizes on the intertidal community (at a scale larger than the individual patches), the cover of sessile species was measured in the study area and on a rocky platform where large predators had not been removed (control area). Percent cover was evaluated by means of a $30 \times 30 \mathrm{~cm}$ string-grid quadrats with 100 
intersection points. The quadrats were applied continuously, covering the whole surface of platforms. Because the control area was not replicated (standard deviations were obtained from different quadrats in a single platform) and patch sizes were not properly interspersed in the study area (not all sizes in each platform), we did not statistically compare the 2 areas.

Regression analyses of data were carried out using the Statistical Analysis System programs (SAS version 6.03). Cover data expressed as percentage were transformed to arcsin, and tested for normality and homogeneity of variance (Sokal \& Rohlf 1981).

\section{RESULTS}

Bare rock patches smaller than $25 \mathrm{~cm}^{2}$ were about 10 -fold more abundant than larger patches in the barnacle-covered areas. As patches increased in size their frequency progressively decreased (Fig. 1a). No patches larger than ca $2500 \mathrm{~cm}^{2}$ were observed in the field. The total area (sum of patch areas in different size-classes) of patches smaller than $25 \mathrm{~cm}^{2}$ was larger than that of patches between 25 and $500 \mathrm{~cm}^{2}$. The total area of the largest patches (500 to $2500 \mathrm{~cm}^{2}$ ) was, however, about 3.4-fold larger than that of the smallest ones (Fig. 1b).
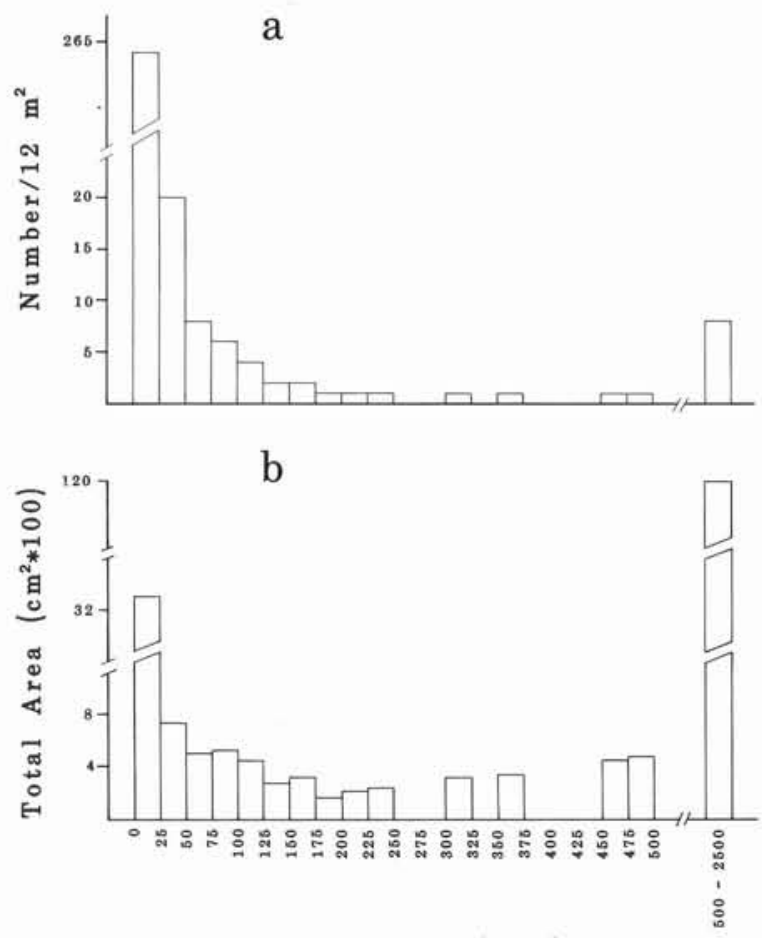

Patch Area $\left(\mathrm{cm}^{2}\right)$

Fig. 1. (a) Size frequency of patches of bare rock in stands of barnacles at semi-sheltered sectors of Las Cruces. (b) Total area covered by different patch size classes
The relationship between perimeter $(\mathrm{Pe})$ and area (A) of these patches was $\mathrm{Pe}=6.25 \mathrm{~A}^{0.49}\left(\mathrm{r}^{2}=0.97, \mathrm{p}=\right.$ $0.0001, \mathrm{n}=22$ ). The perimeter of patches, because of their irregular shape, was longer than expected in a perfect circle $\left(\mathrm{Pe}=3.54 \mathrm{~A}^{0.5}\right.$. Analysis of covariance for intercepts: $p=0.0001$ ).

In all patches studied, the mussel Perumytilus purpuratus recruited only onto the adult barnacle walls that formed the border of patches. The smallest recruits ( 0.3 to $1.0 \mathrm{~mm}$ long) were observed in the angle between the barnacle wall and the bare rock surface. Only one layer of recruits was observed around the perimeter of patches (Fig. 2), before mussels formed 'micro-beds' (see below). No mussels were observed to recruit directly to bare rock. Two mussels, about $2.0 \mathrm{~mm}$ long, were observed to roll into the center of patches, but they were removed (presumably by waves) in the following $10 \mathrm{~d}$. On the other hand, barnacles recruited directly on the bare rock surface of patches (Fig. 2). Occasionally, barnacle cyprids recruited onto the walls of adult barnacles along the patch borders. These recruits were never more than ca $3 \%$ of the recruits found on bare rock, and did not cover more than ca $1 \%$ of the perimeter. Thus, they were not considered in the analyses.

After $130 \mathrm{~d}$, mussels between 0.3 and $3.0 \mathrm{~mm}$ long occupied the entire perimeter of all patches under $21.3 \mathrm{~cm}^{2}$, forming a 'micro-bed' that precluded accurate counts of individuals (see Fig. 2). Thereafter, new mussels recruited mostly on the byssal threads of previously settled individuals.

When the number of newly recruiting mussels and barnacles were regressed against patch area, $130 \mathrm{~d}$ after patch opening, a critical patch area of $35.5 \mathrm{~cm}^{2}$ was determined, where the number of new mussel and barnacle recruits was the same (Fig. 3). Below the critical patch area, newly recruited mussels outnumbered barnacles, above it, the number of barnacle recruits was progressively larger than that of mussels. The best regression model between the number of barnacle recruits $(\mathrm{N})$ and area $(\mathrm{A})$ was linear $(\mathrm{N}=-27.7+3.5 \mathrm{~A}$, $\left.r^{2}=0.96, p=0.0001\right)$. The best regression model between the number of mussel recruits versus area was exponential $\left(\mathrm{N}=27.55 \mathrm{~A}^{0.35}, \mathrm{r}^{2}=0.90, \mathrm{p}=0.0001\right)$.

Fig. 3 shows a minimal patch area for barnacles to recruit onto bare rock. Barnacles recruited at very low rates in patches under $10 \mathrm{~cm}^{2}$ (pers. obs.) and these recruits disappeared from the substratum after only a few days.

The percentage of the patch surface covered by barnacles or mussels is a function of the recruitment of new individuals and their growth once settled. In patches smaller than $21.3 \mathrm{~cm}^{2}$ the mussel cover increased significantly with time (Table 1 ). Some of these patches became entirely covered by 'micro-beds' 


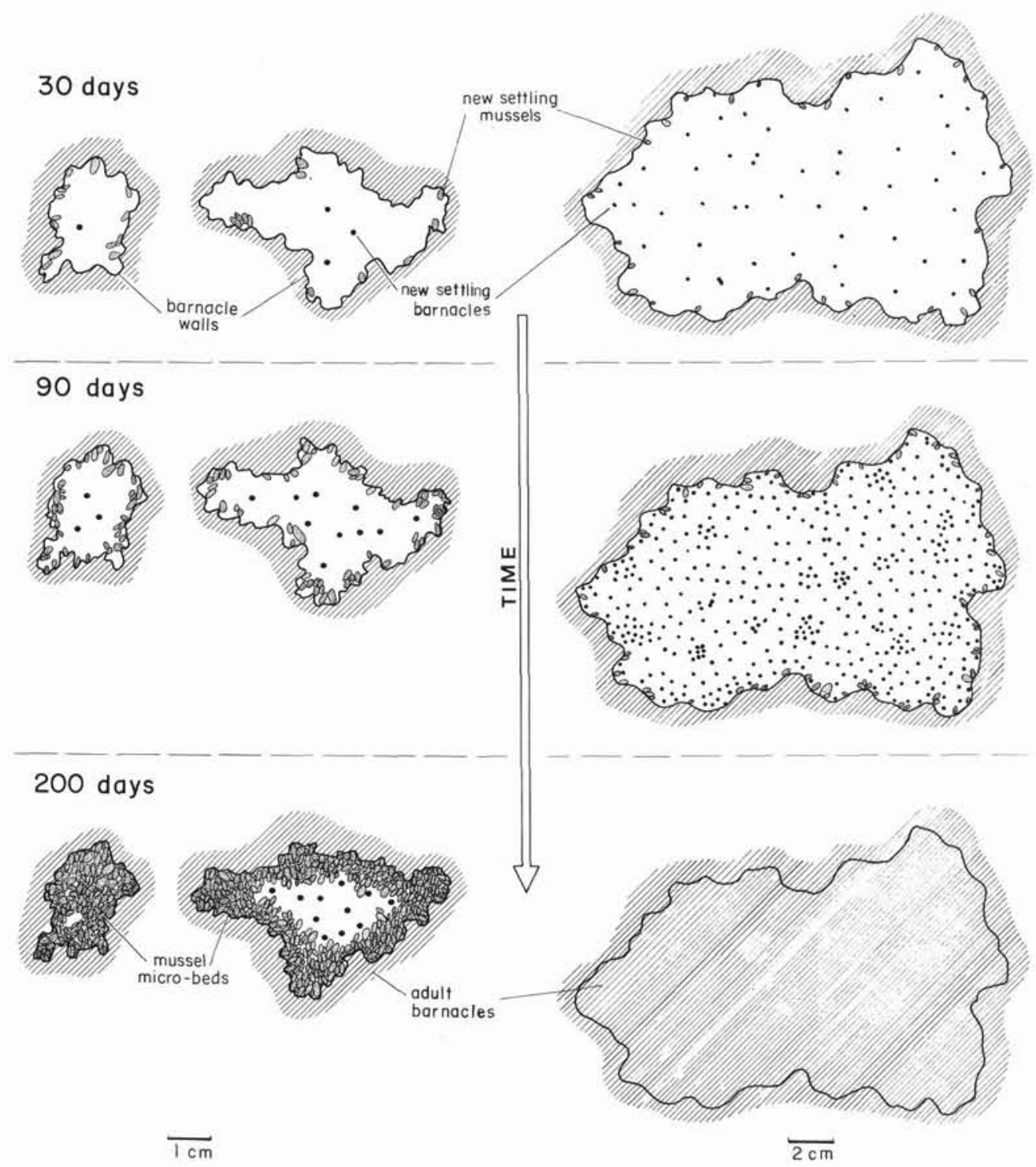

Fig. 2. Field-map showing 2 small and 1 large natural patch of bare rock in the barnacle beds. The same patches are shown at 3 different times during the study. Note different scales for small and large patches. Recruits were drawn out of proportion with respect to patch size. White area: bare rock; striped area: adult barnacles

of mussels in about $200 \mathrm{~d}$. On the other hand, only in 3 patches larger than $21.3 \mathrm{~cm}^{2}\left(\geq 37.0 \mathrm{~cm}^{2}\right)$ did the mussel cover increase significantly $(\mathrm{p} \leq 0.05)$ with time (Table 1). These larger patches were completely covered by barnacles in about $200 \mathrm{~d}$ (Fig. 2, Table 1). Note that there were no patches between 21.3 and $37.0 \mathrm{~cm}^{2}$, and the critical patch area found by regressions of number of recruits $\left(35.5 \mathrm{~cm}^{2}\right)$ lies between these values.

Table 2 shows the cover of sessile species in the study area, where patches were located and large predators removed, and in a control area where large predators were present. An increase in mussel cover in the study area with respect to the control area was observed after $220 \mathrm{~d}$ from the beginning of the obser- vations. Algae were scarce throughout the study, and only ephemeral species were observed. Observations were discontinued because large Heliaster helianthus invaded the study area, preying upon barnacles and mussels. The starfish left patches of bare rock ranging from 400 to $2200 \mathrm{~cm}^{2}$. Ninety days after the invasion of $H$. helianthus the mussel cover was again similar to the control area and a 'homogeneous' layer of newly recruiting barnacles was observed on the rocks.

\section{DISCUSSION}

Previous studies on the exposed rocky intertidal of central Chile showed that once predators (mainly Con- 


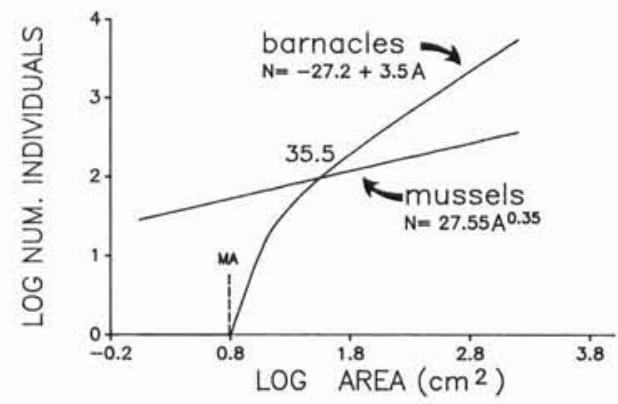

Fig. 3. Regressions of the number of newly recruited mussels and barnacles in relation to patch area at Day 130. Linear regression for barnacles: $\mathrm{r}^{2}=0.96, \mathrm{p}=0.0001, \mathrm{n}=22$. Exponential regression for mussels: $r^{2}=0.90, p=0.0001$, $\mathrm{n}=22$. The number 35.5 denotes the critical patch area $\left(\mathrm{cm}^{2}\right)$ where the number of new-recruiting mussels and barnacles are the same. MA: minimum patch area for successful barnacle recruitment (see text)

Table 1. Perumytilus purpuratus. Linear regressions of percent cover $(\%)$ of mussels versus time (d) for all patches studied. a: intercept $(\%$ cover $)$, b: slope $\left(\%\right.$ cover $\left.d^{-1}\right), r^{2}$ : determination coefficient, p: significance level

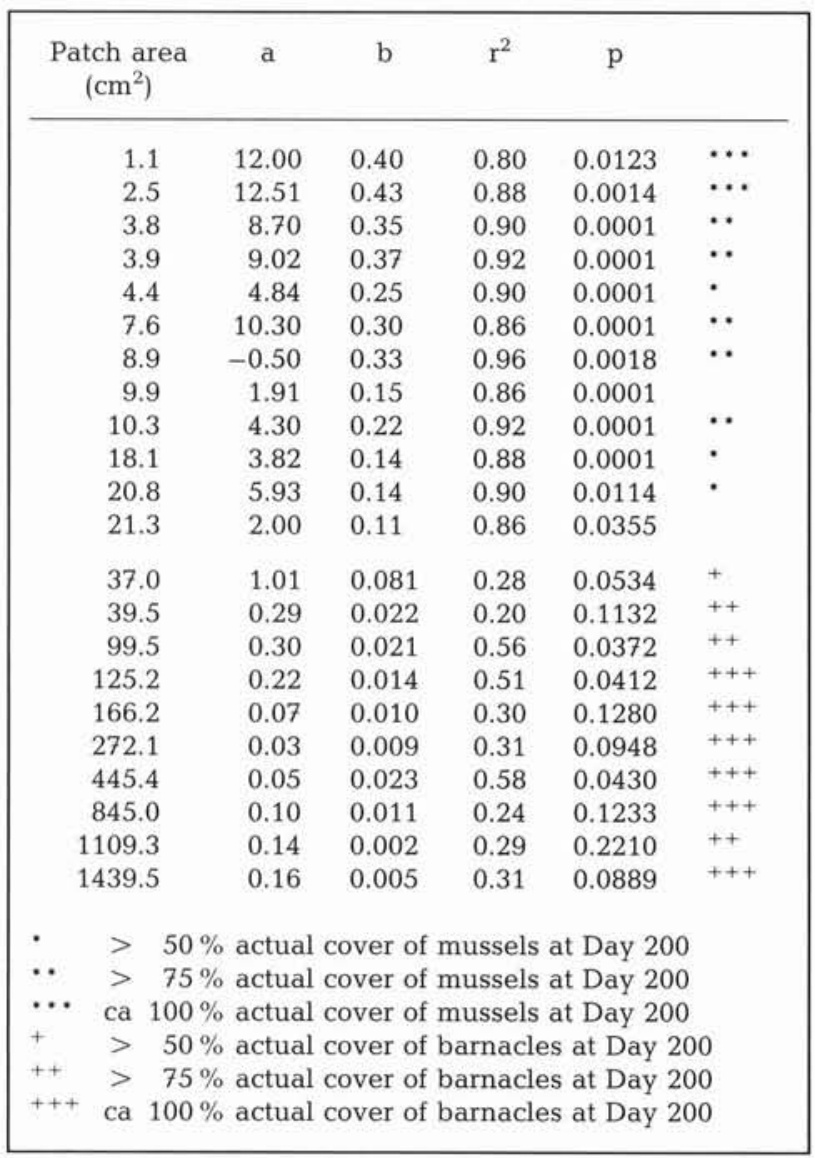

cholepas concholepas) remove the competitively superior mussel Perumytilus purpuratus from rocks, the substratum is readily monopolized by chthamaloid barnacles, which then remain in the system for long
Table 2. Percent cover (mean \pm SE) of sessile species in the study area (large predators excluded) and control area (predators present), at the beginning of the study, $220 \mathrm{~d}$ later, and $90 \mathrm{~d}$ after large Heliaster helianthus invaded the study area ( $310 \mathrm{~d}$ from the beginning)

\begin{tabular}{|c|c|c|c|}
\hline Species & $\begin{array}{l}\text { Beginning } \\
\text { of study }\end{array}$ & $\begin{array}{l}220 \mathrm{~d} \\
\text { later }\end{array}$ & $\begin{array}{l}90 \mathrm{~d} \text { after } \\
\text { H.helianthus } \\
\text { invaded }\end{array}$ \\
\hline \multicolumn{4}{|l|}{ Study area } \\
\hline $\begin{array}{l}\text { Adult barnacles }{ }^{a} \\
(>1 \mathrm{~mm})\end{array}$ & $69.1 \pm 5.7$ & $56.5 \pm 5.2$ & $43.1 \pm 7.1$ \\
\hline $\begin{array}{l}\text { New-recruiting } \\
\text { barnacles }^{\text {a }}(\leq 1 \mathrm{~mm})\end{array}$ & $16.8 \pm 5.9$ & $5.7 \pm 0.7$ & $17.3 \pm 1.6$ \\
\hline Mussels & $3.6 \pm 2.7$ & $12.3 \pm 2.0$ & $1.1 \pm 1.1$ \\
\hline Algae & - & $11.7 \pm 3.8^{\mathrm{b}}$ & - \\
\hline Bare rock & $10.5 \pm 2.4$ & $12.2 \pm 2.7$ & $38.5 \pm 7.0$ \\
\hline \multicolumn{4}{|l|}{ Control area } \\
\hline $\begin{array}{l}\text { Adult barnacles }{ }^{a} \\
(>1 \mathrm{~mm})\end{array}$ & $65.0 \pm 7.3$ & $62.2 \pm 5.7$ & $63.2 \pm 8.5$ \\
\hline $\begin{array}{l}\text { New-recruiting } \\
\text { barnacles }^{\mathrm{a}}(\leq 1 \mathrm{~mm})\end{array}$ & $21.5 \pm 7.4$ & $8.5 \pm 0.6$ & $10.5 \pm 1.7$ \\
\hline Mussels & $3.5 \pm 1.4$ & $2.5 \pm 0.5$ & $0.7 \pm 0.5$ \\
\hline Algae & $0.2 \pm 0.2$ & $4.0 \pm 2.7^{b}$ & - \\
\hline $\begin{array}{l}\text { Bare rock } \\
\text { a Jehlius cirratus and } \\
\text { b Ephemeral algae: } P \\
\text { mussels) }\end{array}$ & $\begin{array}{l}9.8 \pm 0.8 \\
\text { Chthamalus } \\
\text { orphyra colu }\end{array}$ & $\begin{array}{l}22.7 \pm 3.7 \\
\text { scabrosus } \\
\text { mbina, Ulva s }\end{array}$ & $\begin{array}{l}25.7 \pm 10.5 \\
\text { sp. (settled on }\end{array}$ \\
\hline
\end{tabular}

periods of time (Castilla \& Durán 1985, Durán \& Castilla 1989). Although these barnacle beds are continually disrupted by biological or mechanical forces, and bare rock is made available for new colonizers, no evidence of recolonization by mussels has been observed for several years (Durán \& Castilla 1989). In the present study we showed that, in a semi-sheltered habitat, $P$. purpuratus did not recruit directly on the bare rock surface of patches, but only on the walls of adult barnacles that form the patch borders. On the other hand, barnacles did recruit on the bare rock surface of patches.

Newly recruiting mussels outnumbered newly recruited barnacles in all patches with an area smaller than $35.5 \mathrm{~cm}^{2}$ and conversely in larger patches the number of newly recruited barnacles was larger than that of mussels. Since mussels mostly recruited in one layer around the border of patches, the substratum available for mussel recruitment may be thought of as a narrow stretch of barnacle walls, which increases linearly with increasing patch perimeter (see Fig. 2). On the other hand, barnacles recruited to the bare rock, so the substratum available to them is a direct function of the area of the patch. If the size of newly recruiting 
barnacles and mussels is similar, the number of recruits onto different patch sizes should be proportional to the availability of their respective substrata (i.e. barnacle walls and bare rock). Given the empirical relationship between perimeter and area of patches $(\mathrm{Pe}=$ $6.25 \mathrm{~A}^{0.45}$ ), the availability of barnacle walls for mussels will be the same as the availability of bare rock for barnacles when patch size is $38.5 \mathrm{~cm}^{2}$, which is similar to the critical patch area found by counts of the number of recruits $\left(35.5 \mathrm{~cm}^{2}\right)$. The slight difference is probably due to the larger size of mussel recruits. Moreover, the general relationship between the number of recruits in different patch sizes was similar to the relationship between perimeter and area of patches. These observations suggest that, in central Chile, larval availability of both mussels and barnacles is not limiting, and further that in the platforms studied mussel recruitment is limited by the availability of barnacle walls.

In our study monopolization of patches of bare rock by Perumytilus purpuratus occurred only in small patches $\left(\leq 21.3 \mathrm{~cm}^{2}\right)$. As patch size increased, the chance for barnacles to monopolize the substratum also increased. We did not follow the fate of mussel recruits after the large patches were completely convered by barnacles because the study area was disturbed by the invasion of large starfish Heliaster helianthus. We have observed, however, that isolated mussel recruits (not forming 'micro-beds') between 1 and $2 \mathrm{~mm}$ long are not usually able to grow among adult barnacles, but are excluded by them. In other cases, isolated mussels grow among barnacles and reach adult sizes, but do not form beds and eventually die. Once $P$. purpuratus forms a bed they are able to overgrow barnacles (Paine et al. 1985) and the bed acts as a collector of new recruits (Moreno et al. 1986, this study).

Barnacles did not successfully recruit in patches smaller than ca $10 \mathrm{~cm}^{2}$. Newly recruited barnacles usually died before being overgrown by mussels. We think that the continuous grazing effected by the small herbivores Littorina araucana and Collisella spp., which seek refuge among barnacles during low tides and forage at nights or changing tides (Viviani 1975), could be responsible for the mortality of newly recruiting barnacles (limpets can kill newly settled barnacles; see Dayton 1971 and Branch 1981 for review). This hypothesis assumes that herbivores have no effect on newly recruiting mussels on the patch borders (e.g. mechanical restrictions) and that they do not venture to the center of large patches.

The probability that mussels recolonize intertidal areas in the habitat studied here, shifting from a barnacle-dominated to a mussel-dominated substratum, will depend on the size frequency of patches. If barnacle beds are disrupted in several small patches the availability of substratum for mussels would be larger than if only few large patches are produced. Although under natural conditions small patches $(<$ critical patch area) are abundant, the total area covered by them is several times smaller than that covered by large patches and their effect on the intertidal might be insignificant. Small patches are produced mainly by Acanthocyclus crabs (Navarette \& Castilla 1988), juveniles of Heliaster helianthus, and the sea plovers Aprhiza virgata and Arenaria interpres (pers. obs.). Large patches are generally produced by juveniles and adults of Concholepas concholepas and large Heliaster helianthus (Viviani 1975, Castilla \& Durán 1985). By excluding large $H$. helianthus and $C$. concholepas we observed a slight increase in the cover of mussels, resulting mainly from the monopolization of small patches (see Table 1). Thus, size-selective exclusion of predators in this habitat may have not only quantitative but qualitatively different effects on the community structure.

Acknowledgements. It is a pleasure to acknowledge Jorge Alvarado and Carmen Espoz for their helpful assistance in the field and discussion of ideas. Jorge Alvarado also helped us measuring patches in the lab. Pablo Marquet, Mauricio Muñoz, and Patricio Ojeda helped us with earlier versions of the manuscript. We also thank Denise D. Idler, Bruce A. Menge, Thomas H. Suchanek, David S. Wethey, Sylvia B. Yamada, and 3 anonymous referees for their valuable suggestions and comments. The work was supported by Research Project DIUC 018/88, P. Universidad Católica de Chile. S.A.N. also acknowledges financial support given by Beca de Instructor (Fellowship) of the Departamento de Ecología, P. Universidad Católica de Chile and by Fulbright Commission, USA. The paper was written during the sabbatical leave of J.C.C. at the Department of Zoology, University of Washington, and support given by Fundación Andes, Fulbright Commission, and the University of Washington is sincerely appreciated.

\section{LITERATURE CITED}

Bayne, B. L. (1964). Primary and secondary settlement in Mytilus edulis L. J. Anim. Ecol. 33: 513-523

Branch, G. M. (1981). The biology of limpets: physical factors, energy flow, and ecological interactions. Oceanogr. mar. Biol. A. Rev. 19: 235-380

Castilla, J. C. (1981). Perspectivas de investigación en estructura y dinámica de comunidades intermareales rocosas de Chile Central. II. Depredadores de alto nivel trófico. Medio Ambiente (Chile) 5: 190-215

Castilla, J. C. (1988). Earthquake-caused coastal uplift and its effects on rocky intertidal kelp communities. Science 242: $440-443$

Castilla, J. C., Durán, L. R. (1985). Human exclusion from the rocky intertidal zone of central Chile: the effects on Concholepas concholepas (Gastropoda). Oikos 45: 391-399

Dayton, P. K. (1971). Competition, disturbance, and community organization: the provision and subsequent utilization of space in rocky intertidal communities. Ecol. Monogr, 41: 351-389

Durán, L. R., Castilla, J. C. (1989). Variation and persistence of the middle rocky intertidal community of central Chile with and without human harvesting. Mar. Biol. 103: 555-562 
Eyster, L. S., Pechenik, J. A. (1987). Attachment of Mytilus edulis L. larvae on algal and byssal filaments is enhanced by water agitation. J. exp. mar. Biol. Ecol. 114: 99-110

Harger, J. A. (1972). Competitive coexistence. Maintenance of interacting associations of the sea mussels Mytilus edulis and Mytilus californianus. Veliger 14: 387-410

Keough, M. J., Downes, B. J. (1982). Recruitment of marine invertebrates: the role of active larval choices and early mortality. Oecologia (Berl.) 54: 348-352

Lively, C. M., Raimondi, P. T. (1987). Desiccation, predation, and mussel-barnacle interactions in the northern Gulf of California. Oecologia (Berl.) 74: 304-309

Lewis, J. R. (1964). The ecology of rocky shores. English University Press, London

McGrath, D., King, P. A., Gosling, E. M. (1988). Evidence for the direct settlement of Mytilus edulis larvae on adult mussel beds. Mar. Ecol. Prog. Ser. 47: 103-106

Menge, B. A. (1976). Organization of the New England rocky intertidal community: role of predation, competition, and environmental heterogeneity. Ecol. Monogr. 46: 355-393

Moreno, C. A., Lunecke, K. M., Lopez, M. I. (1986). The response of an intertidal Concholepas concholepas (Gastropoda) population to protection from man in southern Chile and the effects on benthic sessile assemblages. Oikos 46: 359-364

Navarrete, S. A., Castilla, J. C. (1988). Foraging activities of Chilean intertidal crabs Acanthocyclus gayi MilneEdwards et Lucas and A. hassleri Rathbun. J. exp. mar. Biol. Ecol. 118: 115-136

Paine, R. T. (1966). Food web complexity and species diversity. Am. Nat. 100: 65-75

Paine, R. T., Castilla, J. C., Cancino, J. (1985). Perturbation and recovery patterns of starfish dominated intertidal assemblages in Chile, New Zealand and Washington State. Am. Nat. 125: 679-691

Paine, R. T., Levin, S. A. (1981). Intertidal landscapes: disturbance and the dynamics of pattern. Ecol. Monogr. 51: $145-178$

This article was submitted to the editor
Petersen, J. H. (1984a). Establishment of mussel beds: attachment behavior and distribution of recently settled mussels (Mytilus californianus). Veliger 27: 7-13

Petersen, J. H. (1984b). Larval settlement behavior in competing species: Mytilus californianus Conrad and $M$. edulis $\mathrm{L}$. J. exp. mar. Biol. Ecol. 82: 147-159

Petraitis, P. S. (1978). Distributional patterns of juvenile Mytilus edulis and Mytilus californianus. Veliger 21: 288-292

Seed, R. (1969). The ecology of Mytilus edulis L. (Lamellibranchiata) on exposed rocky shores. 1 . Breeding and settlement. Oecologia (Berl.) 3: 277-316

Seed, R. (1976). Ecology. In: Bayne, B. L. (ed.) Marine mussels: their ecology and physiology. IBP 10, Cambridge Univ. Press, London, p. 13-65

Sokal, R. R., Rohlf, F. J. (1981). Biometry, 2nd edn. W. H. Freeman, San Francisco

Suchanek, T. H. (1978). The ecology of Mytilus edulis L. in exposed rocky intertidal communities. J. exp. mar. Biol. Ecol. 31: 105-120

Suchanek, T. H. (1979). The Mytilus californianus community: studies on the composition, structure, organization, and dynamics of a mussel bed. Ph.D. dissertation, Dept of Zoology, Univ. of Washington, Seattle

Suchanek, T. H. (1981). The role of distrubance in the evolution of life history strategies in the intertidal mussels Mytilus edulis and Mytilus californianus. Oecologia (Berl.) 50: $143-152$

Suchanek, T. H. (1986). Mussels and their role in structuring rocky shore communities. In: Moore, P. G., Seed, G. (eds.) The ecology of rocky coasts. Columbia Univ. Press, New York, p. 70-96

Viviani, C. A. (1975). Las comunidades marinas litorales en el Norte Grande de Chile. Publ. Ocasional, Lab. Ecol. Marina, Iquique, Chile, p. 1-196

Yamada, S. B., Peters, E. E. (1988). Harvest management and the growth and conditions of submarket-size sea mussels, Mytilus californianus. Aquaculture 74: 293-299

Manuscript first received: March 27, 1990

Revised version accepted: August 6, 1990 